\title{
Midiendo al capital social: aplicación del generador de posiciones en el Área Metropolitana de Buenos Aires
}

\author{
Measuring social capital: position generator application in the Metropolitan Area \\ of Buenos Aires
}

\author{
Joaquín Carrascosa \\ joaquin.carrascosa91@gmail.com \\ Instituto de Investigaciones Gino Germani - \\ Universidad de Buenos Aires, Argentina
}

Recepción: 29 Octubre 2020

Aprobación: 11 Febrero 2021

Publicación: 01 Junio 2021

Cita sugerida: Carrascosa, J. (2021). Midiendo al capital social: aplicación del generador de posiciones en el Área Metropolitana de Buenos Aires. Revista Latinoamericana de Metodología de las Ciencias Sociales, 11(1), e088. https://doi.org/10.24215/18537863e088
Resumen: En las ciencias sociales resulta fundamental disponer de instrumentos que nos permitan medir fenómenos complejos difíciles de observar de manera directa. Un ejemplo de esto es el capital social, cuya importancia ha crecido en los estudios de estratificación social y desigualdades de clase en las últimas décadas. Este artículo presenta las principales propuestas de operacionalización y creación de indicadores cuantitativos del capital social presentes en la bibliografía especializada (generador de nombres, generador de posiciones y generador de recursos) y detalla el proceso de construcción del generador de posiciones a partir de datos de una encuesta probabilística del Área Metropolitana de Buenos Aires. En primer medida, se presentan los fundamentos de los principales instrumentos de medición que existen para analizar el capital social; luego se avanza con una descripción de los procedimientos metodológicos y técnicos requeridos para la construcción del generador de posiciones, incluyendo los módulos de sintaxis de Stata y SPSS desarrollados. A continuación, se presentan datos descriptivos y correlaciones entre las medidas de capital social y factores de estratificación social adscriptos y adquiridos. Finalmente, se realiza un análisis de componentes principales de las medidas del generador de posiciones para construir una medida del capital social que integre sus distintas dimensiones.

Palabras clave: Capital social, Generador de posiciones, Estratificación social.

Abstract: In the social sciences it is fundamental to have instruments that allows us to measure complex phenomena that are hard to observe through survey data. An example of this is social capital, that has had growing importance in the last decades in social stratification and class inequalities studies. This paper presents the main proposals for operationalization and creation of quantitative indicators of social capital present in the specialized literature (position generator, name generator, resource generator) and details the process of elaboration of the position generator based on survey data from a probabilistic sample of the Metropolitan Area of Buenos Aires. The basis of the main instruments for measuring social capital are presented along with the methodological and technical procedures required to obtain the indicators from the position generator, including the Stata and SPSS syntax modules that where developed. After that, descriptive and correlational results 
are presented for each measure of social capital and social stratification factors. Finally, a principal component analysis is performed to build a measure of social capital that integrates it 's different dimensions.

Keywords: Social capital, Position generator, Social stratification.

\section{INTRODUCCIÓN}

El capital social ha ganado importancia en los debates de estratificación y análisis de clases sociales a partir de miradas multidimensionales sobre la desigualdad social. La incorporación de este concepto se basa en la potencialidad que tienen los individuos de invertir en relaciones y así acceder a recursos para concretar logros, bajo la idea de que no sólo es importante lo que uno sabe sino también a quién conoce (Lin, 2001, p. 96).

En América Latina el capital social ha sido estudiado como un activo que combina actitudes de confianza, reciprocidad y cooperación a partir de las cuales las comunidades pueden obtener beneficios, particularmente para el desarrollo y la salida de la pobreza a partir de políticas públicas impulsadas por organismos internacionales como el Banco Interamericano de Desarrollo y el Banco Mundial (Atria et al, 2003; Durston, 2003; Kliksberg y Tomassini, 2000). Por otro lado, se ha analizado la importancia del capital social para el logro ocupacional a nivel individual, particularmente en Chile y Uruguay (Espinoza, Rey y Barozet, 2017). El capital social se encuentra distribuido desigualmente según clase social, pero también ayuda en procesos de superación de la pobreza y movilidad social en los sectores bajos (Rey, 2014 y 2017). Además, el capital social familiar es utilizado como mecanismo de empleo por personas en las posiciones más bajas de la estructura de estratificación social en México (Brunet, 2017).

En la Argentina la familia es fundamental para la construcción de mantenimiento de vínculos de sociabilidad y los sectores bajos se vinculan en mayor medida en el ámbito barrial (De Grande, 2010 y 2015). Los lazos familiares son importantes para la reproducción en las clases populares (Dalle, 2016) y, a su vez, los lazos familiares y de amistad son importantes como mecanismo de acceso al empleo en las personas de todas las clases sociales (Pérez, 2008; Carrascosa, 2021). Además, estudios cualitativos han resaltado la movilización de recursos a partir de lazos sociales en actividades económicas informales y para la organización comunitaria (Feldman y Murmis, 2002; Mallimaci y Graffigna, 2002; Merlinsky, 2001; Wyczykier, 2003; Chávez Molina, 2010).

Para llevar adelante cualquier tipo de trabajo cuantitativo es fundamental poder medir los fenómenos sociales que queremos observar. Entonces, si queremos investigar la distribución del capital social en la estructura de clases, su papel en procesos de logro de estatus o formación de clases, su rol como mecanismo de acceso a mejores ocupaciones... ¿cómo hacemos para medir los recursos a los que las personas pueden acceder a través de sus lazos sociales?

En la bibliografía especializada existen distintas propuestas de cómo hacerlo (generador de nombres, generador de posiciones, generador de recursos), habitualmente a partir de datos de encuestas que tienen secciones dedicadas para la construcción de un instrumento de medición. En este trabajo se expondrán las distintas propuestas de medición haciendo foco en el generador de posiciones y se realizará una aplicación práctica de este a partir de datos provenientes de la encuesta "Reproducción y movilidad social en trayectorias familiares y cursos de vida" del Programa de Investigación sobre Análisis de Clases Sociales (PI-Clases, IIGGUBA) dirigida por la Dra. Ruth Sautu, el Dr. Pablo Dalle, la Dra. Paula Boniolo y el Dr. Rodolfo Elbert. La encuesta fue realizada en el Área Metropolitana de Buenos Aires entre los años 2015 y 2016 y su unidad de análisis es personas de ambos sexos de entre 25 y 65 años. La muestra es probabilística y cuenta con un total de 1065 casos. 
Algo a destacar es que la encuesta del PI-Clases es la primera en la Argentina que incluye el generador de posiciones como metodología de medición del capital social. Otras investigaciones han utilizado el generador de nombres con datos del Observatorio de la Deuda Social (De Grande, 2015); además, el Programa de Investigación sobre la Sociedad Argentina Contemporánea (PISAC) se ha propuesto investigar con la Encuesta Nacional sobre Relaciones Sociales (ENRS) las redes de vínculos sociales, el capital social, los circulación de recursos, etc. (Kessler, 2017).

El trabajo se estructura de la siguiente manera. Luego de esta introducción se plantean algunas cuestiones sobre la medición de fenómenos complejos en las ciencias sociales y se desarrollan las bases teóricas del concepto de capital social desde la teoría de redes. A continuación, se presentan algunas de sus propuestas de medición más utilizadas junto con una explicación detallada de los fundamentos del generador de posiciones. Posteriormente, se detalla cómo construir el generador de posiciones a partir de micro-datos de encuesta. De modo complementario, se presentan algunos resultados de las medidas del generador de posiciones en relación con variables clásicas de estratificación social y su distribución según clases sociales. Finalmente, se presenta la elaboración de un índice de capital social a partir de un análisis de componentes principales y también se realiza una serie de análisis de componentes principales que integran factores adscriptos (estatus ocupacional y educación del padre) y factores adquiridos (estatus ocupacional y educación del encuestado).

Los módulos de sintaxis para construir el generador de posiciones a partir de datos de encuesta en Stata y en SPSS se encuentran disponibles en línea en https://github.com/JoaquinCarrascosa/positiongenerator/.

\section{LA MEDICIÓN DE FENÓMENOS COMPLEJOS EN CIENCIAS SOCIALES}

Las ciencias seleccionan propiedades de sus objetos de estudio con el fin de establecer entre ellos una serie de relaciones. Según Lazarsfeld (1973), el descubrimiento de estas es la meta principal de la investigación científica. Sin embargo, en las ciencias sociales la elección de estas propiedades o atributos del objeto y su medición precisa implican cierta complejidad. En esta línea, Blumer (1982) señala la relevancia de la apropiada elaboración de esquemas teóricos que delimiten la naturaleza de dichas propiedades y sus relaciones en términos abstractos. El énfasis se encuentra puesto en los conceptos, ya que estos representan herramientas que nos permiten llevar a cabo un correcto entrelazamiento entre el pensamiento y el mundo empírico.

Para caracterizar un objeto de estudio necesitamos construir variables a partir de un proceso de operacionalización que nos permitan medir objetos complejos. Este proceso implica la definición del concepto y sus distintas dimensiones, la selección de los indicadores a observar empíricamente y la síntesis de dichos indicadores en un índice (Lazarsfeld, 1973, p. 37).

\section{Algunas NOCiONES TEÓRICAS: EL CAPITAL SOCIAL DESDE LA PERSPECTIVA DE REDES}

El capital social se define desde una teoría de redes como recursos "insertos" (embedded) en una estructura social a los que acceden individuos que los movilizan en acciones con un propósito determinado (Lin, 2001, p. 29). ${ }^{1}$ El capital social posee tres componentes que ligan la estructura y la acción: a) los recursos insertos en la estructura social; b) las oportunidades que brindan; y c) la acción de movilizar los recursos con un objetivo determinado. El generador de posiciones mide el nivel de acceso de cada individuo a los recursos insertos en la estructura social pero no mide ni a los recursos propiamente dichos ni su movilización en concreto. Esta noción del capital social como atributo individual se distingue de las visiones que lo conciben como bien común o atributo comunitario (Putnam, 1993; Portes, 1998).

Los recursos a los que se puede acceder a partir del capital social son bienes materiales o simbólicos, como la riqueza, el poder o la reputación. El acceso a estos recursos requiere de una inversión en relaciones interpersonales y de la inserción en redes sociales. Estos permiten aumentar los beneficios de las acciones 
que los individuos llevan adelante en diversos ámbitos, como el económico, el mercado laboral, el político o el comunitario. Para ello es fundamental la capacidad de agencia individual; para lograr estos beneficios es necesario movilizar los recursos que se tienen, por ejemplo, para concretar una búsqueda laboral (Lin, 2001).

Esta teoría se encuentra ordenada por una serie de postulados básicos (Lin, 2001). Los recursos insertos en las estructuras sociales se encuentran distribuidos desigualmente; las posiciones en la estructura social conforman jerarquias piramidales según los recursos que poseen, su nivel de autoridad y la cantidad de personas que ocupan estas posiciones.

La interacción entre actores ocurre a partir del principio de homofilia, entre actores con niveles socioeconómicos similares que se encuentran en posiciones cercanas o adyacentes en la estructura social y tienen estilos de vida similares (McPherson, Smith-Lovin \& Cook, 2001). Por otro lado, el principio de heterofilia (Granovetter, 1973; Lin, 2005, p. 14) implica que mientras uno más se aleje de su círculo íntimo, más posible es encontrar individuos con recursos distintos de los que uno mismo posee. Este tipo de lazos puede ser menos intenso, pero amplían el abanico de cantidad, calidad y cualidad de los recursos accesibles.

Los lazos sociales pueden ser fuertes, con vínculos estables y duraderos, como las relaciones familiares o de amistades cercanas; estos son importantes por su nivel de reciprocidad y la confianza que implican. Por otro lado, hay lazos de tipo débil, como amigos, conocidos o contactos, que brindan información o recursos que no se encuentran necesariamente en las relaciones más cercanas. Habitualmente se considera que el estudio de los lazos débiles es fundamental para analizar las estructuras de oportunidades, ya que estos pueden favorecer la movilidad social al funcionar como puentes que conectan distintas redes (Granovetter, 1973).

Si bien esta línea teórica se ha concentrado en el capital social desde una perspectiva de estratificación social, también puede pensárselo desde perspectivas relacionales del análisis de clases. El capital social puede ser considerado un factor clave en los procesos de formación de la clase de servicios en tanto consolida privilegios y favorece la reproducción de las desigualdades de clase (Li, Savage y Warde, 2008). A su vez estudios con un enfoque multidimensional de las clases sociales que incluye el capital social (bourdiano) revelaron una creciente polarización entre los extremos de la estructura de clase y la fragmentación de las clases medias (Savage et al., 2013).

\section{LAS PROPUESTAS DE MEDICIÓN DEL CAPITAL SOCIAL}

El método más habitual de medición del acceso al capital social es el generador de nombres. Este funciona sobre la base de preguntarle al encuestado acerca de sus contactos en ciertos ámbitos de relaciones establecidos (barrio, trabajo, hogar, etc.) o bien preguntarle sobre las personas con quienes tiene más relación (que no vivan en el mismo hogar). Las preguntas permiten construir una lista de personas relevantes para ego, en la que también se detalla información como el origen y tipo de vínculo, la frecuencia de contacto, la distancia física, las características del contacto (ocupación, genero, edad, etc.), a partir de la cual puede reconstruirse la red social del encuestado (Burt, 1992; Campbell, Marsden y Hurlbert, 1986).

Las ventajas que propone esta metodología son que se puede formular un mapeo de red centrada en ego y a su vez es posible focalizarse en distintos ámbitos de relaciones. Sin embargo, esta medición tiene el inconveniente de carecer de un marco de muestreo de las relaciones y de tener un sesgo hacia los lazos más fuertes (Lin, 2001).

Otra forma de medir el acceso al capital social, desarrollada más recientemente, es el generador de recursos (Van der Gaag y Snijders, 2004; Van der Gaag, Snijders y Flap, 2008). Para construirlo se pregunta a los encuestados si conocen a alguien que posea recursos de distinto tipo (económicos, cualificaciones, información, etc.) y a quien pueda recurrir si lo necesita.

Lo valioso de esta medida es que es más directa que las demás, considerando que la definición del capital social se centra en los recursos insertos a los que los individuos acceden. En cambio, las otras medidas evalúan el capital de manera más indirecta a través de la posición ocupacional de los contactos, y deben asumir 
teóricamente que acceder a personas con ciertas ocupaciones implica el acceso a los recursos. Se destaca la utilidad del generador de recursos para estudiar los procesos de logro de estatus, pero su desventaja es que los recursos a analizar dependen fuertemente del contexto, por lo que es difícil de comparar entre sociedades distintas.

En este trabajo, se utilizará el generador de posiciones (Lin y Dumin, 1986). Este utiliza una muestra de posiciones ocupacionales destacadas en la estructura social y pide a los encuestados que indiquen si tienen o no contactos en ellas. Algunas preguntas adicionales son si el contacto es un familiar o un amigo/conocido, su género y la frecuencia con la que se encuentran.

Esta medición se focaliza en la centralidad del trabajo como organizador de la vida en las sociedades modernas. Al estar basada en una muestra de ocupaciones (por ejemplo, médicos, albañiles, operarios de fábrica, empleados administrativos, etc.), permite evaluar el acceso a distintos niveles de recursos poseídos por contactos, como los ingresos, educación, autoridad en el trabajo, entre otros.

El generador de posiciones favorece la recolección de información sobre la posición social ocupada por los contactos para reconstruir el espectro de recursos accesibles a ego. Sus ventajas son varias: el instrumento fue construido a partir de una base teórica sólida, lo suficientemente universal como para aplicar a distintas poblaciones, y la construcción de indicadores con la información que brinda se encuentra mayoritariamente estandarizada. Estos dos aspectos facilitan la comparabilidad entre estudios (Van der Gaag \& Snijders, 2004). A su vez, otro aspecto favorable es que se basa en una muestra de posiciones en la jerarquía social y se encuentra libre de contenido relativo a los ámbitos y roles de las relaciones. También resulta económico de relevar por la rapidez con la que pueden responderse las preguntas y tiene bajas tasas de no respuesta. Su desventaja principal es la falta de especificidad de las relaciones que se observan (Lin, 2001).

En el nivel teórico, el generador de posiciones se basa en dos supuestos fundamentales. Primero, asume que la distribución de recursos en una sociedad refleja la jerarquía piramidal de la estructura ocupacional de dicha sociedad, por lo que se apoya principalmente en un enfoque de estratificación social basado en agregados ocupacionales. Segundo, supone que el hecho de conocer a alguien en determinada ocupación significa tener acceso a los recursos que esta provee (Verhaeghe y Li, 2015).

El generador de posiciones se encuentra estandarizado internacionalmente y se encuentra validado por numerosos estudios cuantitativos y cualitativos alrededor del mundo: Lin y Dumin (1986), Völker y Flap (1999), Angelusz y Tardos (1991), Erickson (1995), Van der Gaag, Snijders y Flap (2008), entre muchos otros. $^{2}$

Las medidas de acceso al capital social que el generador de posiciones permite reconstruir son las siguientes: la cantidad de contactos (volumen de la red), el promedio de estatus accedido, el mayor estatus accedido, el rango de acceso (diferencia entre el mayor y el menor), el total de estatus accedido, una medida compuesta (que pondera el volumen, el máximo y el rango a partir de un análisis de componentes principales) y, finamente, una medida basada en clases sociales. A su vez, es posible distinguir entre los recursos relativos a familiares y los relativos a amigos y conocidos.

Cada una de estas medidas destaca una dimensión del capital social y se basa en distintas perspectivas sobre la estratificación social (Verhaegue y Li, 2015, p. 169). 
FIGURA 1

Esquema de medidas de capital social

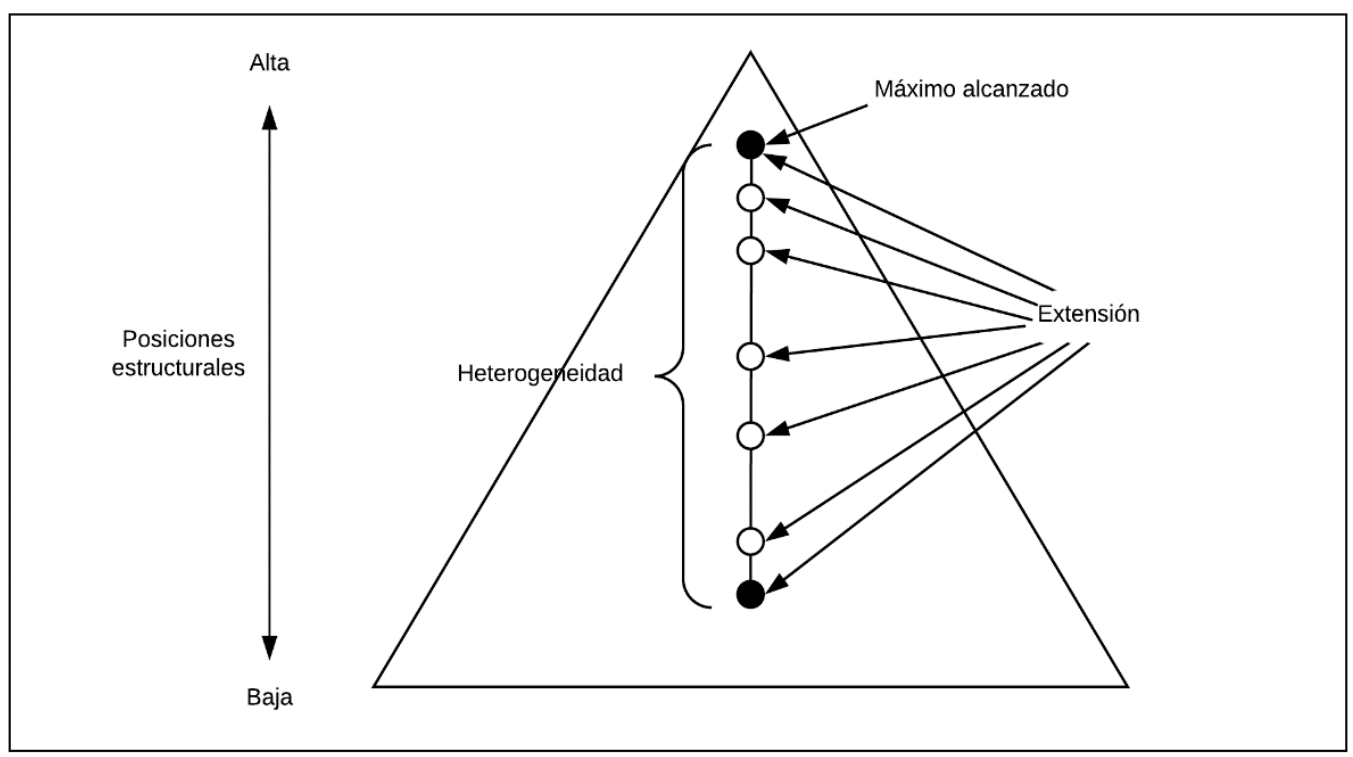

Fuente: Lin (2001, p. 62)

El volumen de recursos en la red se mide a partir de la cantidad de ocupaciones de la lista del generador de posiciones en las que el encuestado tiene contactos. La idea central es que mientras más extensa sea la red, se accederá a más recursos. Esta medida no distingue entre las ocupaciones a las que se accede y por lo tanto ignora las desigualdades en la distribución de recursos en la sociedad (Verhaeghe y Li, 2015).

Para el resto de las medidas, no sólo importa la cantidad de contactos sino también la calidad de los recursos que estos pueden brindar. Las medidas de promedio, máximo, rango y la compuesta se basan en escalas de estatus ocupacional continuas con una perspectiva funcionalista sobre la estratificación social.

El promedio de estatus de los recursos disponibles se calcula dividiendo la suma de los puntajes en una escala de estatus por el total de ocupaciones accedidas. Esta medida se basa en que las ocupaciones con mayor estatus están asociadas a más y mejores recursos y en que es la calidad del conjunto de la red la que tiene mayor importancia a la hora de llevar adelante una acción instrumental.

El máximo estatus disponible en la red de recursos se corresponde con el estatus del contacto con una posición más alta en la estructura de estratificación. Esta medida se basa en observar lo más alto que una persona puede alcanzar (upper reachability), ya que el mejor acceso a recursos y poder se ubicaría en las posiciones más altas de la estructura de estratificación (Lin, 2001, p. 62).

El rango de estatus accedido se calcula como la diferencia entre el puntaje máximo y el mínimo de estatus al que se tiene acceso. Esta medida se basa en la idea de la heterogeneidad de recursos (resourse heterogeneity) y refleja el rango vertical de recursos a los que puede accederse; mientras más diversa sea una red de contactos, mejor (Verhaeghe y Li, 2015).

La medida compuesta propone una perspectiva multidimensional de los recursos insertos en las redes, para lo cual combina los distintos componentes del capital social mencionados anteriormente. Esta medida es menos utilizada que las anteriores y se calcula sobre la base de una suma ponderada (utilizando el peso de estas variables en un análisis de componentes principales) de la estandarización del volumen, el máximo y el rango accedido.

Finalmente, aunque menos usada, existe una medida del capital social basada en los enfoques relacionales de clases sociales, que utiliza en general el esquema de Goldthorpe. Para calcularla se cuenta la cantidad de contactos que el encuestado tiene en cada posición de clase social. Esta se diferencia del resto en tanto hace distinciones cualitativas en torno a los recursos a los que se accede. No se trata únicamente de la calidad ni 
la cantidad de los recursos accedidos, sino que tener contactos en distintas posiciones de clase social puede brindar distintos tipos de recursos. A su vez, el uso de categorías de clase social permite distinguir efectos positivos y negativos del capital social (Verhaeghe y Li, 2015).

\section{De LA TEORía A LA PRÁCTICA}

Para el armado de variables típicas en el campo de estratificación social y análisis de clases existen sintaxis o módulos disponibles en línea que son de uso habitual por parte de los investigadores. Por ejemplo, las herramientas de conversión utilizadas en este trabajo para las variables de estratificación y clases son las provistas por Ganzeboom y Treiman (2010). Sin embargo, no existe una herramienta de uso generalizado para la construcción del generador de posiciones a partir de datos de encuesta, por lo que parte importante de este trabajo consistió en su elaboración siguiendo las pautas presentes en la bibliografía.

Para la construcción del generador de posiciones se utilizó la sección de la encuesta del PI-Clases dedicada a relevar aspectos relativos a los lazos sociales de los encuestados.

\section{Sección Nro. 9: Lazos sociales del/a encuestado/a}

"Ahora quisiera preguntarle sobre las personas con las que usted se relaciona en su vida cotidiana. Le voy a mencionar algunas ocupaciones. Quisiera saber si tiene usted familiares o amigos que se dediquen a esa ocupación. Cuando digo 'amigos' me refiero a alguien que conoce su nombre y con quien se tiene suficiente confianza para iniciar una conversación y llamarse por teléfono, siempre y cuando no sea una relación estrictamente laboral."

Se preguntó por separado cada ocupación para familiares y luego para amigos y también se diferenció entre quienes conocían a un hombre, a una mujer o a ambos. También se relevó la frecuencia con que el encuestado se visita o habla por teléfono con cada contacto.

En este caso, el criterio para definir qué es un amigo fue el de conocerse de nombre y tener suficiente confianza para iniciar una conversación o llamarse por teléfono para cuestiones no ligadas a lo laboral. Otros criterios posibles son el de conocerse de nombre y tratarse de "vos" o preguntar al encuestado si en caso de encontrarse de improviso en la calle sabría el nombre de esa persona y ambos podrían entablar una conversación (Van der Gaag, Snijders y Flap, 2008). 
FIGURA 2

Preguntas del cuestionario utilizadas para la elaboración del generador de posiciones ${ }^{3}$

\begin{tabular}{|c|c|c|c|c|c|}
\hline Ocupación & Familiar & Amigo & \multicolumn{2}{|c|}{ Contacto } & \\
\hline \multirow[t]{2}{*}{ 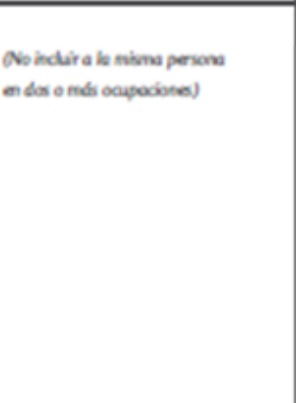 } & \multirow[t]{2}{*}{ 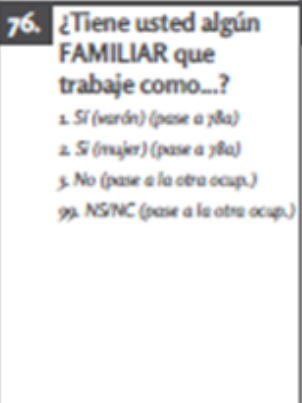 } & \multirow[t]{2}{*}{ 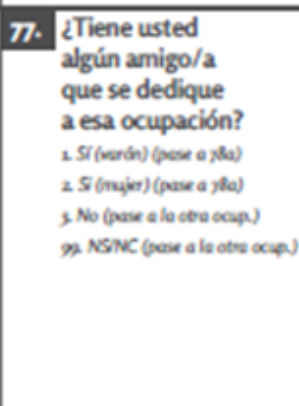 } & \multicolumn{2}{|c|}{ 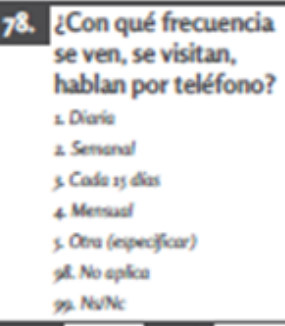 } & \\
\hline & & & $\begin{array}{l}\text { 78.a } \\
\text { Familiar }\end{array}$ & \begin{tabular}{|l|} 
78. b \\
Amigo
\end{tabular} & \\
\hline \multirow[t]{4}{*}{ a Albanil } & & & & & n76a \\
\hline & & & & & $v m a$ \\
\hline & & & & & v8aa \\
\hline & & & & & visba \\
\hline \multirow{4}{*}{$\begin{array}{l}\text { b. Empleado/a } \\
\text { administrativo/a en } \\
\text { empresa privada o el } \\
\text { Estado }\end{array}$} & & & & & $v 760$ \\
\hline & & & & & $v m b$ \\
\hline & & & & & v8sac \\
\hline & & & & & v 86 \\
\hline \multirow[t]{4}{*}{ c. Obrero/a u operario/a } & & & & & $\sqrt{76 c}$ \\
\hline & & & & & $v \pi c$ \\
\hline & & & & & v8ac \\
\hline & & & & & vysbc \\
\hline \multirow[t]{4}{*}{ d. Gerente/a de empresa } & & & & & v76d \\
\hline & & & & & 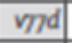 \\
\hline & & & & & visad \\
\hline & & & & & v/8bd \\
\hline \multirow[t]{4}{*}{ e. Médico/a } & & & & & nछe \\
\hline & & & & & vme \\
\hline & & & & & v78ce \\
\hline & & & & & visbe \\
\hline \multirow{4}{*}{$\begin{array}{l}\text { f. Dueffo/a de negocio / } \\
\text { pequeffo comercio }\end{array}$} & & & & & vof \\
\hline & & & & & vाff \\
\hline & & & & & v78af \\
\hline & & & & & visbf \\
\hline \multirow[t]{4}{*}{ g. Abogado/a contador/a } & & & & & v76g \\
\hline & & & & & $v 79$ \\
\hline & & & & & visag \\
\hline & & & & & v/85g \\
\hline
\end{tabular}

Fuente: Elaboración propia en base a Encuesta Pi-Clases (2016).

La valoración referida a las posiciones ocupacionales se basa en la escala ISEI (Ganzeboom, De Graaf y Treiman, 1992). Dicha escala presenta un enfoque continuo sobre la estratificación ocupacional, que captura diferencias entre grupos sociales según niveles educativos y de ingresos entre categorías ocupacionales de la CIUO, maximizando el rol de la ocupación como variable interviniente entre la educación y el ingreso. 
CUADRO 1

Ocupaciones presentes en el cuestionario con su código de CIUO-08 y valor en escala ISEI

\begin{tabular}{|c|c|c|}
\hline Ocupación & CIUO 08 & ISEI \\
\hline Albañil & 7112 & 22,57 \\
\hline Empleado administrativo & 4110 & 43,33 \\
\hline Obrero u operario & 8100 & 23,41 \\
\hline Médico & 2210 & 88,70 \\
\hline Gerente de empresa & 1200 & 72,94 \\
\hline $\begin{array}{c}\text { Dueño de negocio o } \\
\text { pequeño comercio }\end{array}$ & 5221 & 35,34 \\
\hline Abogado o contador & 2611 & 86,72 \\
\hline $\begin{array}{c}\text { Servicio doméstico o } \\
\text { niñera }\end{array}$ & 9111 & 14,21 \\
\hline
\end{tabular}

Fuente: Elaboración propia sobre la base de Ganzeboom y Treiman (2010) y ILO (2012)

Con base en esta información se construye el generador de posiciones. Para ello se elaboró una sintaxis en Stata en SPSS , siguiendo inicialmente como guía la versión propuesta por Van der Gaag (2005) (https://gi thub.com/JoaquinCarrascosa/positiongenerator/), que realiza los siguientes procedimientos:

- A partir de las variables originales se construyen variables dicotómicas que determinan si la persona conoce o no a alguien en esa posición ocupacional (sin importar si conoce a un hombre, a una mujer o a ambos). Para cada ocupación se construyen tres variables de este tipo: el conocimiento o no de un familiar, el conocimiento o no de un amigo y el conocimiento o no de una persona (sin importar si es amigo, familiar o ambos).

- Las variables anteriores son sumadas para determinar la Cantidad de contactos de cada encuestado, separando la cantidad de familiares, la cantidad de amigos y la cantidad general (para la suma general, tener solamente un familiar o tener tanto familiar como amigo es indistinto).

- A partir de las variables dicotómicas se computa a cada ocupación su valor de escala ISEI correspondiente. Sobre la base de estos valores se procede a:

- calcular el valor Máximo al que accede el encuestado (en este caso el valor máximo posible es 88,7 , correspondiente a quienes conocen un médico).

- calcular el valor mínimo al que accede el encuestado.

- calcular el Rango restando el mínimo al máximo (el rango únicamente se calcula para quienes tienen al menos dos contactos).

- se computa el Total de acceso sumando el ISEI para cada ocupación a la que accede el encuestado.

- se obtiene el Promedio de las ocupaciones accedidas, dividendo el total accedido según la cantidad de contactos (el promedio se calcula sobre la cantidad de ocupaciones a las que accede el encuestado, no sobre las ocho ocupaciones presentes en la encuesta).

Para cada una de estas medidas pueden obtenerse por separado los valores correspondientes a los familiares, a los amigos y el total (sin diferenciar entre un amigo, un familiar o a ambos). También se obtiene la cantidad de contactos de clase media al sumar únicamente las ocupaciones pertenecientes a esta clase (médico, abogado o contador, gerente, empleado administrativo y comerciante) y la cantidad de contactos de clase obrera (obrero u operario, albañil y empleada doméstica o niñera). 


\section{El generador de posiciones en el Área Metropolitana de Buenos Aires}

A continuación, se presentan algunos estadísticos resumen de las medidas de capital social del generador de posiciones junto con algunas variables de estratificación social clásicas (las variables son cinco: ocupación del encuestado, ocupación del padre y primera ocupación del encuestado - siendo estas tres medidas a partir de la escala ISEI -, años de educación del encuestado y años de educación del padre del encuestado) ${ }^{4}$.

CUADRO 2

Estadísticos resumen de medidas de capital social y variables de estratificación social

\begin{tabular}{|c|c|c|c|c|c|}
\hline Variable & $\mathbf{n}^{5}$ & Media & $\begin{array}{c}\text { Desvio } \\
\text { estándar }\end{array}$ & $\begin{array}{c}\text { Error } \\
\text { estándar }\end{array}$ & $\begin{array}{c}\text { Coeficiente de } \\
\text { variabilidad } \\
\text { (\%) }\end{array}$ \\
\hline $\begin{array}{c}\text { ISEl encuestado } \\
\begin{array}{c}\text { ISEl primera ocupación del } \\
\text { encuestado }\end{array}\end{array}$ & 1044 & 42,6 & 22,2 & 0,69 & 52,1 \\
\hline $\begin{array}{c}\text { Años de educación } \\
\text { encuestado }\end{array}$ & 1065 & 12,0 & 4,2 & 0,13 & 34,7 \\
\hline ISEl ocupación del padre & 1014 & 35,9 & 19,4 & 0,61 & 54,1 \\
\hline $\begin{array}{c}\text { Años de educación del } \\
\text { padre }\end{array}$ & 1021 & 8,5 & 4,9 & 0,15 & 57,5 \\
\hline Cantidad de contactos & 1065 & 4,0 & 1,8 & 0,06 & 45,4 \\
\hline Cantidad de lazos fuertes & 1065 & 2,5 & 1,6 & 0,05 & 62,4 \\
\hline Cantidad de lazos débiles & 1065 & 2,9 & 1,9 & 0,06 & 64,7 \\
\hline Promedio de capital social & 1046 & 44,5 & 15,9 & 0,49 & 35,6 \\
\hline Rango de capital social & 982 & 49,5 & 23,8 & 0,76 & 48,1 \\
\hline Máximo de capital social & 1046 & 69,7 & 25,5 & 0,79 & 36,5 \\
\hline Total de capital social & 1046 & 187,5 & 104,6 & 3,23 & 55,8 \\
\hline $\begin{array}{c}\text { Cantidad contactos de clase } \\
\text { media }\end{array}$ & 1065 & 2,5 & 1,6 & 0,05 & 62,9 \\
\hline $\begin{array}{c}\text { Cantidad contactos de clase } \\
\text { obrera }\end{array}$ & 1065 & 1,5 & 1,1 & 0,03 & 74,2 \\
\hline
\end{tabular}

Fuente: Elaboración propia en base a Encuesta Pi-Clases (2016)

También puede observarse la matriz de correlaciones entre dichas variables. Como es de esperar, las variables de estratificación social (adscriptas y adquiridas) se correlacionan fuertemente entre sí. En relación con las medidas de capital social, las medidas de cantidad de contactos tienen un bajo nivel de correlación con las medidas de estratificación. Entre las medidas de capital social, la de promedio accedido es la que se correlaciona con mayor fuerza con las variables de estratificación, mientras que las medidas de total, máximo y rango tienen correlaciones más moderadas. Por otro lado, la cantidad de contactos de clase obrera se correlaciona negativamente con las variables de estratificación social, con el promedio y máximo de capital social y con la cantidad de contactos de clase media. 


\section{GRÁFICO 1}

Elipses de correlación ${ }^{6}$

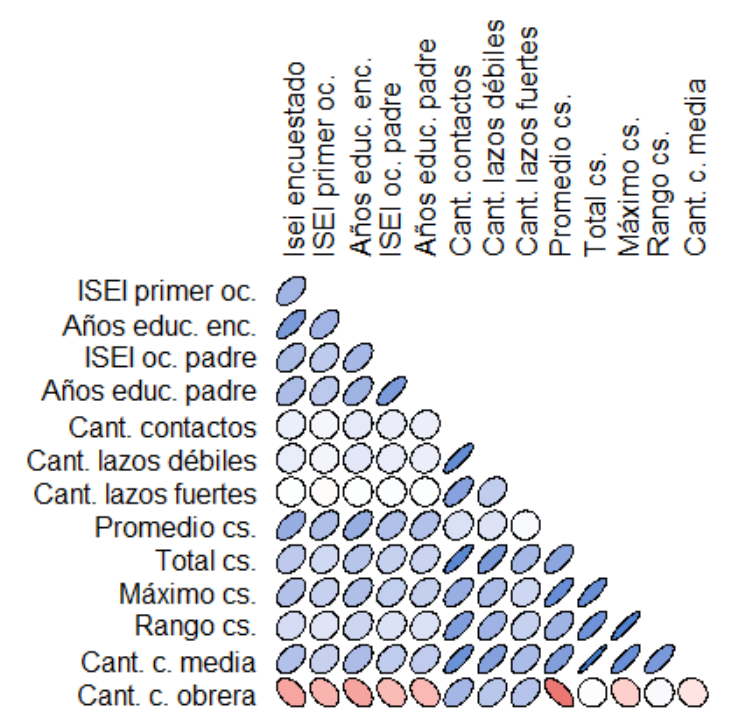

Fuente: Elaboración propia en base a Encuesta Pi-Clases (2016)

\section{GRÁFICO 2}

Gráfico de dispersión de estatus ocupacional del encuestado y promedio de capital social, coloreado según tres grandes clases sociales

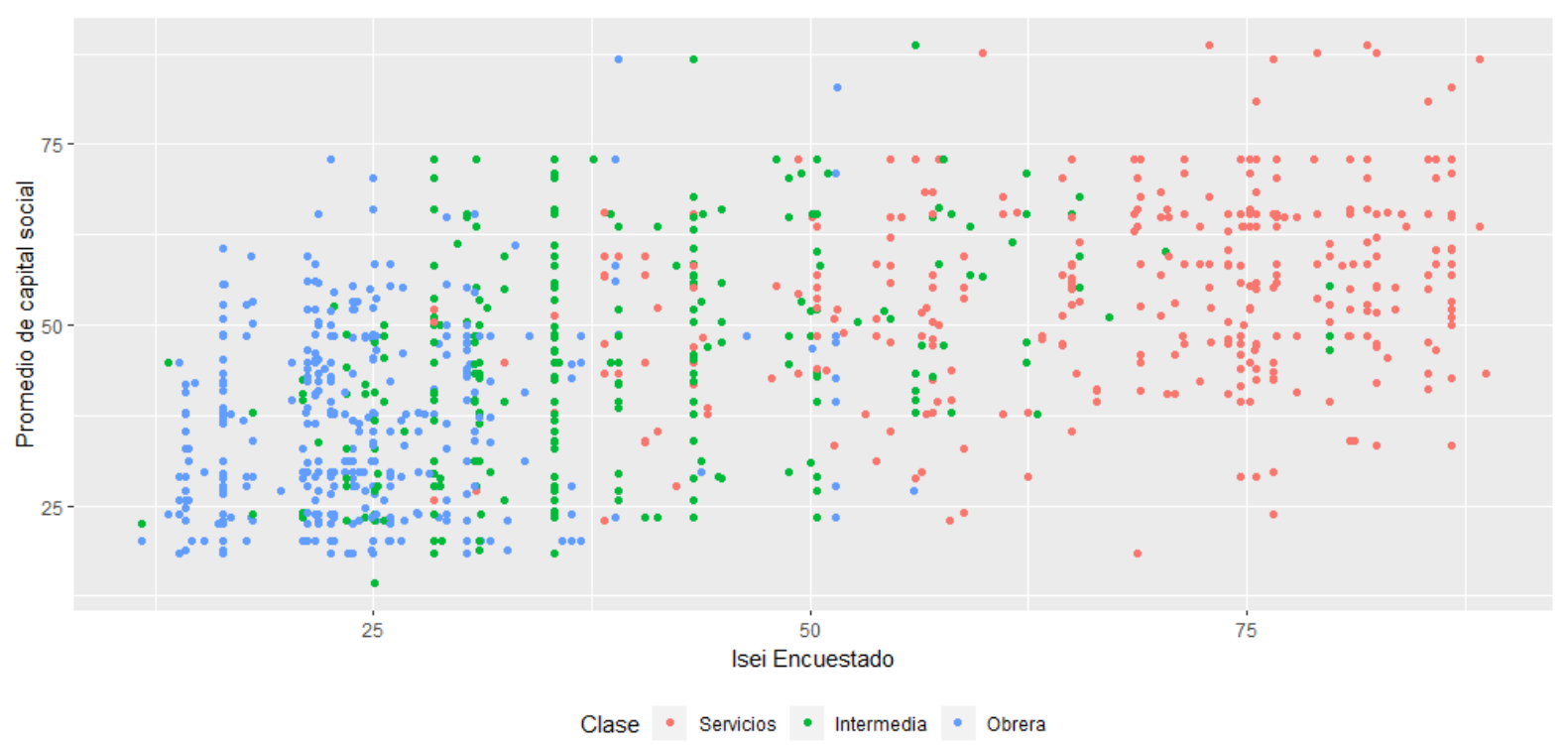

Fuente: Elaboración propia en base a Encuesta Pi-Clases (2016)

La fuerte correlación entre estatus ocupacional y promedio de capital social accedido $(\mathrm{r}=0,576)$ puede observarse en un gráfico de dispersión, en el que se nota un claro ordenamiento según clases sociales. La clase obrera, en celeste, ocupa el sector inferior izquierdo del gráfico (bajo estatus ocupacional y bajo capital social), la clase intermedia ocupa el centro (en verde) y la clase de servicios se ubica principalmente del lado superior derecho (alto estatus ocupacional y alto capital social). 


\section{GRÁFICO 3}

Distribución de densidad de promedio de capital social según clase social

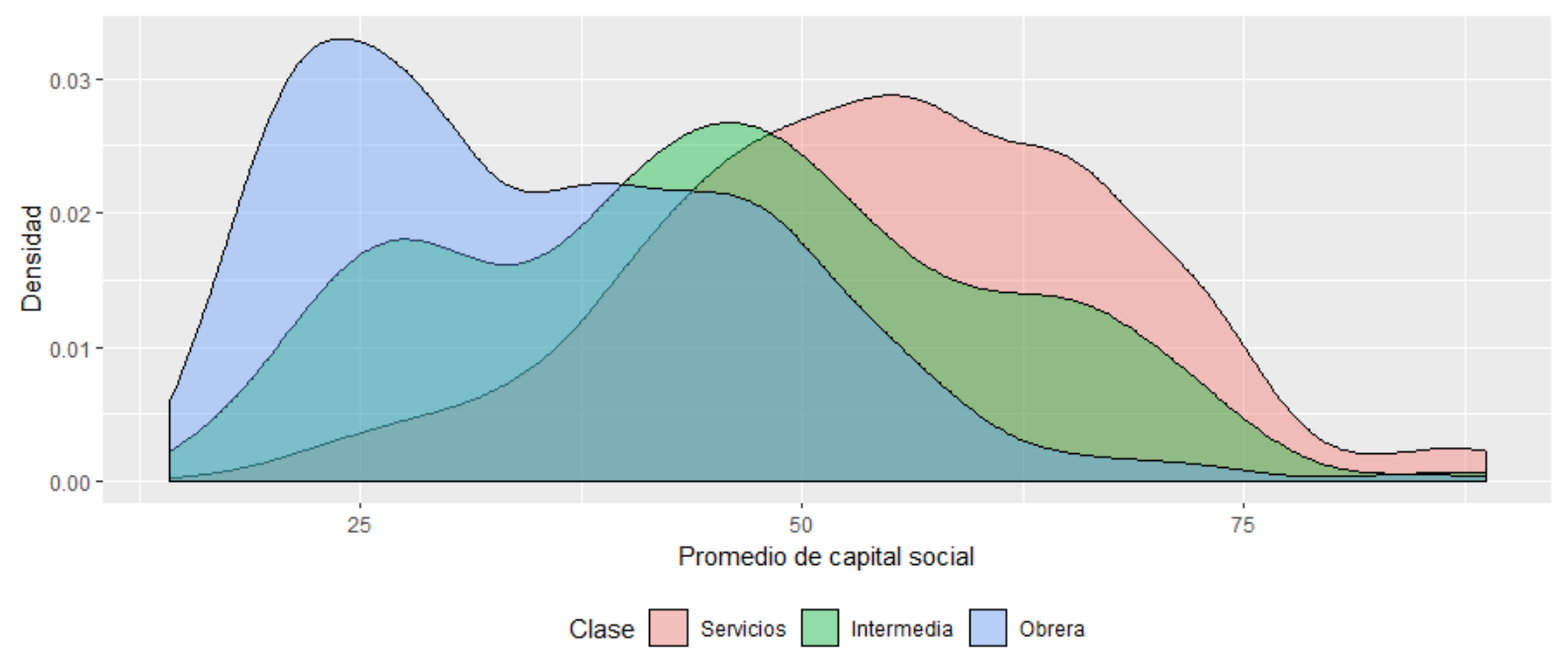

Fuente: Elaboración propia en base a Encuesta Pi-Clases (2016)

También pueden observarse las desigualdades en acceso al capital social entre clases sociales a partir de la distribución de densidad. La clase de servicios es la que tiene mayor acceso al capital social mientras que la clase obrera tiene menores niveles de acceso, con un pico cercano a los 25 puntos.

\section{CONSTRUCCIÓN DE UN ÍNDICE DE CAPITAL SOCIAL A PARTIR DEL ANÁLISIS DE COMPONENTES PRINCIPALES}

Siguiendo las propuestas recientes de la bibliografía especializada (Verhaeghe \& Li, 2015; Espinoza, Rey y Barozet, 2017; Rey, 2017), se realizó un análisis de componentes principales para conocer si existe una estructura factorial subyacente entre distintas medidas del capital social a partir de las cuales puede generarse un indice de capital social. Para ello, se utilizaron tres medidas que refieren a distintas dimensiones del capital social; la medida de volumen (o cantidad de lazos), que mide la extensión de la red; la medida de máximo estatus accedido (upper reachability) y la medida de rango de estatus accedido, basada en la heterogeneidad de los recursos. Como se observó anteriormente, estas variables están fuertemente correlacionadas entre sí.

El análisis de componentes principales (Pearson, 1901) es un método de reducción de dimensiones que permite resumir una gran cantidad de variables en una cantidad menor (componentes) manteniendo la mayor cantidad de información posible. Este tipo de análisis se realiza de manera que el primer componente principal capture la mayor varianza posible (es decir que dé cuenta de la mayor variabilidad en los datos que pueda) y a su vez cada componente subsiguiente captura menos varianza y no se encuentra correlacionado con los otros.

El primer paso para realizar este tipo de análisis es la prueba de Kaiser-Meyer-Olkin (KMO) de adecuación muestral, que nos indica si las variables seleccionadas son apropiadas para un análisis de componentes principales o no. En este caso, alcanza un valor de 0,545 , que se encuentra apenas por encima del mínimo de 0,5 recomendado para continuar con el análisis de componentes principales (Kaiser, 1974). A su vez, la prueba de esfericidad de Bartlett nos indica que el factor resultante tiene una distribución similar a la de Chicuadrado, con lo que se rechaza la hipótesis nula (de que no tenga esta distribución). 
CUADRO 3

Pruebas de Kaiser-Meyer-Olkin (KMO) y esfericidad de Bartlett

\begin{tabular}{|c|c|c|}
\hline \multicolumn{2}{|c|}{ Prueba Kaiser-Meyer-Olkin } & 0,545 \\
\hline \multirow{2}{*}{$\begin{array}{c}\text { Prueba de esfericidad de } \\
\text { Bartlett }\end{array}$} & $\begin{array}{c}\text { Chi-cuadrado } \\
\text { aproximado }\end{array}$ & 2464,7 \\
\cline { 2 - 3 } & gl & 3 \\
\cline { 2 - 3 } & Sig. & 0,000 \\
\hline
\end{tabular}

Fuente: Elaboración propia en base a Encuesta Pi-Clases (2016)

CUADRO 4

Estructura factorial del capital social

\begin{tabular}{|c|c|c|c|}
\hline \multirow{2}{*}{ Componente } & \multicolumn{3}{|c|}{ Eigenvalues } \\
\cline { 2 - 4 } & Total & $\begin{array}{c}\text { \% de la } \\
\text { varianza } \\
\text { explicada }\end{array}$ & \% acumulado \\
\hline 1 & 2,423 & 80,8 & 80,8 \\
\hline 2 & 0,511 & 17,0 & 97,8 \\
\hline 3 & 0,065 & 2,2 & 100,0 \\
\hline $\begin{array}{c}\text { Contribución al componente } \\
\text { (Eigenvectors) }\end{array}$ & Componente 1 & Componente 2 \\
\hline Cantidad & 0,517 & 0,825 & - \\
\hline Máximo & 0,585 & $-0,53$ & - \\
\hline Rango & 0,624 & $-0,18$ & - \\
\hline
\end{tabular}

Fuente: Elaboración propia en base a Encuesta Pi-Clases (2016)

$\mathrm{Al}$ realizar el análisis de componentes principales se observa que el primer componente adquiere un valor de 2,423, lo que explica gran parte de la varianza entre las variables $(80,8 \%)$, mientras que el segundo factor alcanza un valor de 0,511 y explica un 17,0 \% de la varianza (acumulando 97,8 \%). El criterio de Kaiser sugiere tener en cuenta los factores con valores mayores a 1 , mientras que el criterio de varianza sugiere utilizar los factores que alcancen a explicar de manera acumulada aproximadamente entre el $70 \%$ y $80 \%$ de la varianza. En este sentido, como puede observarse en el gráfico de sedimentación, se destaca principalmente el primer componente, aunque el segundo también puede considerarse relevante por la varianza que alcanza a explicar. 
GRÁFICO 4

Gráfico de sedimentación de componentes

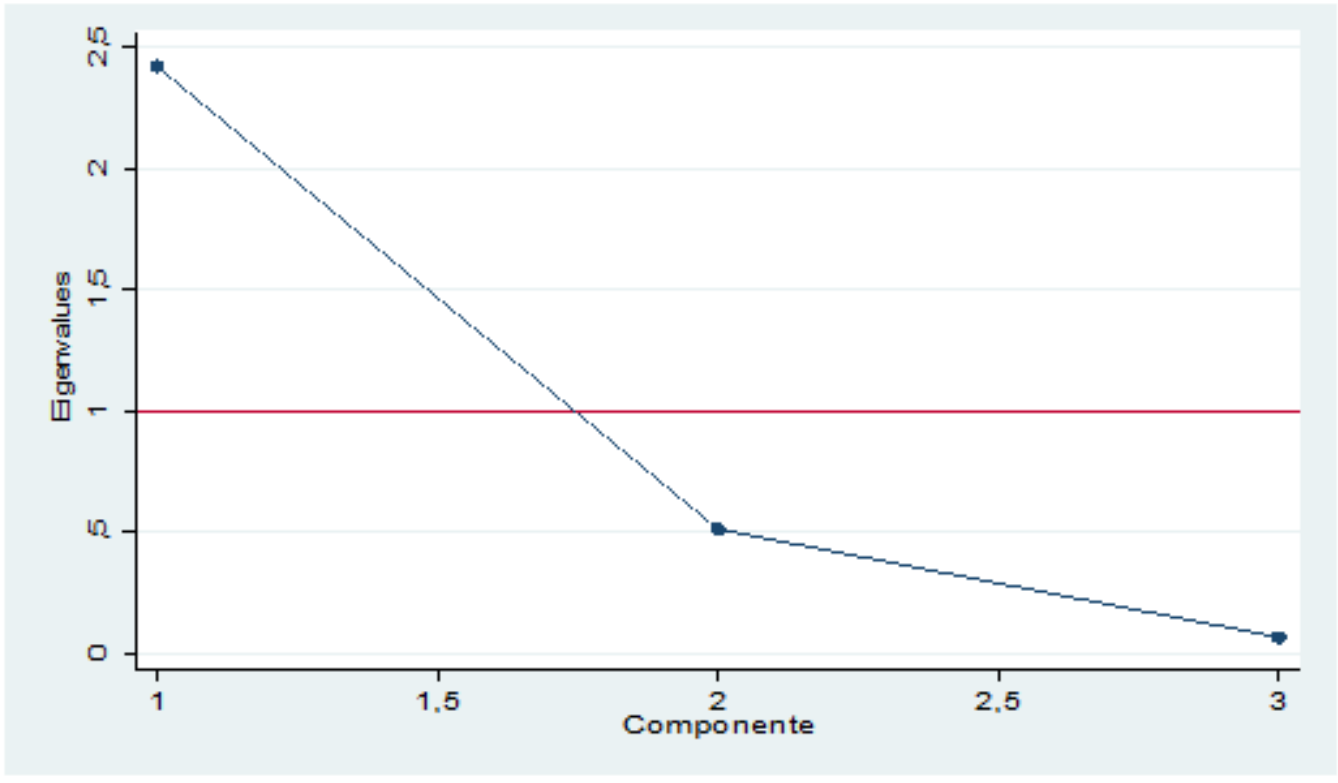

Fuente: Elaboración propia en base a Encuesta Pi-Clases (2016)

Puede observarse que las tres variables contribuyen fuertemente al primer factor, en el siguiente orden: rango de capital social $(0,624)$, máximo de capital social $(0,585)$ y cantidad de contactos $(0,517)$. A su vez, el segundo factor (de menor importancia que el primero) corresponde principalmente a la cantidad de contactos $(0,825)$, mientras que el máximo y rango de capital social aportan negativamente $(-0,53$ y $-0,18)$.

GRÁFICO 5

Gráfico de componentes

\section{Component loadings}

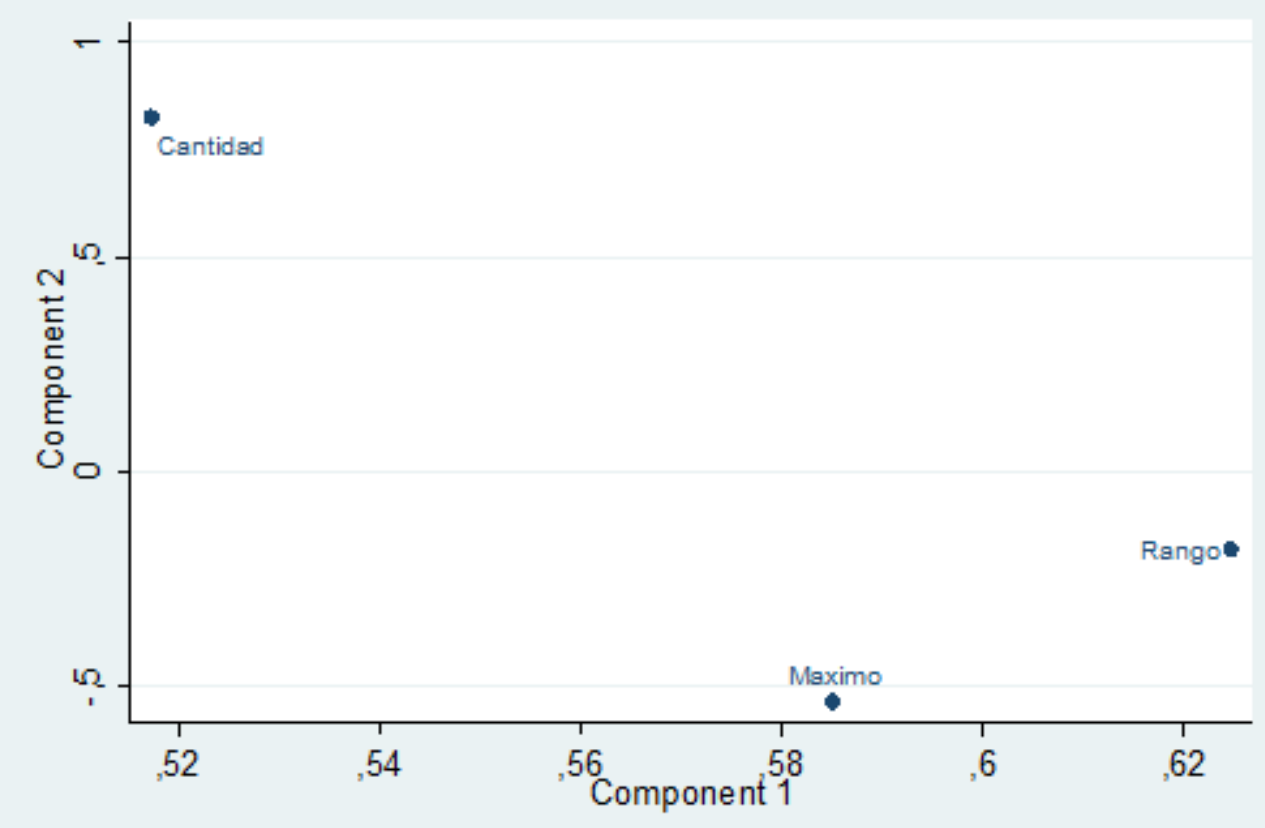


Se presentan a continuación estadísticos descriptivos de la variable resultante del primer factor (índice de capital social). A partir del primer factor se construyó también una medida compuesta en base a la suma ponderada (utilizando como valor de ponderación la contribución de cada variable al primer factor) de las variables de Cantidad, Rango y Máximo dividido tres (la cantidad de variables) ${ }^{7}$.

\section{CUADRO 5}

Estadísticos descriptivos de índice de capital social y medida compuesta

\begin{tabular}{|c|c|c|c|c|c|}
\hline Variables & $\mathrm{n}$ & Media & Mínimo & Máximo & Desvío estándar \\
\hline $\begin{array}{c}\text { Índice de Capital } \\
\text { Social (componente 1) }\end{array}$ & 982 & 0,019 & $-3,169$ & 2,251 & 1,55 \\
\hline $\begin{array}{c}\text { Medida compuesta de } \\
\text { capital social }\end{array}$ & 982 & 25,028 & 5,084 & 34,16 & 9,64 \\
\hline
\end{tabular}

Fuente: Elaboración propia en base a Encuesta Pi-Clases (2016)

\section{CUADRO 6}

Correlaciones entre variables de capital social y estratificación con el índice de capital social

\begin{tabular}{|c|c|c|c|c|c|c|c|c|c|c|c|c|c|c|}
\hline Variables & 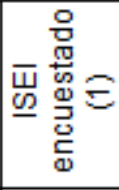 & 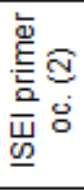 & 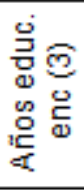 & 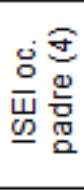 & 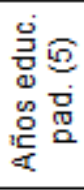 & 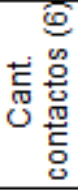 & 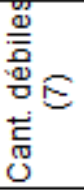 & 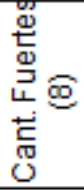 & 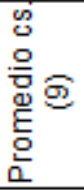 & 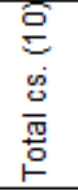 & 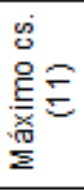 & 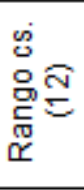 & 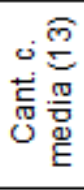 & 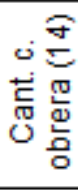 \\
\hline $\begin{array}{c}\text { Indice de } \\
\text { Capital } \\
\text { Social } \\
\text { (component } \\
\text { e 1) }\end{array}$ & 0,299 & $\begin{array}{c}0,19 \\
2\end{array}$ & $\begin{array}{c}0,33 \\
1\end{array}$ & $\begin{array}{c}0,24 \\
1\end{array}$ & $\begin{array}{c}0,23 \\
8\end{array}$ & $\begin{array}{c}0,80 \\
7\end{array}$ & $\begin{array}{c}0,39 \\
5\end{array}$ & $\begin{array}{c}0,62 \\
8\end{array}$ & $\begin{array}{c}0,58 \\
4\end{array}$ & $\begin{array}{c}0,88 \\
6\end{array}$ & $\begin{array}{c}0,91 \\
1\end{array}$ & $\begin{array}{c}0,97 \\
2\end{array}$ & $\begin{array}{c}0,83 \\
6\end{array}$ & $\begin{array}{c}0,03 \\
6\end{array}$ \\
\hline
\end{tabular}

Fuente: Elaboración propia en base a Encuesta Pi-Clases (2016)

Como es de esperar, el índice de capital social se correlaciona fuertemente con las variables de capital social excepto con la variable de cantidad de contactos de clase obrera. También se correlaciona moderadamente con las variables de estratificación social, pero en menor medida que el promedio de capital social (cuadro 3).

\section{ANÁLISIS DE COMPONENTES PRINCIPALES DE FACTORES ADSCRIPTOS Y ADQUIRIDOS}

Una pregunta central a responder en este trabajo es si es relevante la introducción del capital social como un factor de estratificación social que no se encuentra ya contenido por elementos clásicos como el estatus ocupacional y la educación (tanto en orígenes y destinos).

Para ello se realizará una serie de análisis de componentes principales. Por un lado, se analizarán los componentes de los "factores adscriptos" (estatus ocupacional, educación del padre y capital social familiar) y por otro lado, los componentes de los "factores adquiridos" (estatus ocupacional, educación y capital social del encuestado). Esta tarea se llevará adelante dos veces, utilizando dos alternativas distintas de capital social: el promedio accedido y el índice de capital social. ${ }^{8}$ 


\section{CUADRO 7}

Estructura factorial para orígenes sociales (estatus ocupacional, educación del padre e índice de capital social para lazos familiares) y de factores adquiridos (estatus ocupacional, educación e índice de capital social)

\begin{tabular}{|c|c|c|c|c|c|c|c|}
\hline \multirow[b]{2}{*}{ Componente } & \multicolumn{3}{|c|}{$\begin{array}{c}\text { Componentes de factores } \\
\text { adscriptos }\end{array}$} & \multirow[b]{2}{*}{ Componente } & \multicolumn{3}{|c|}{$\begin{array}{c}\text { Componentes de factores } \\
\text { adquiridos }\end{array}$} \\
\hline & Total & $\begin{array}{c}\% \text { de la } \\
\text { varianza } \\
\text { explicada }\end{array}$ & $\begin{array}{c}\% \\
\text { acumulad } \\
0\end{array}$ & & Total & $\begin{array}{c}\% \text { de la } \\
\text { varianza } \\
\text { explicada }\end{array}$ & 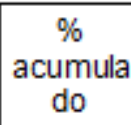 \\
\hline 1 & 1,812 & $60,4 \%$ & $60,4 \%$ & 1 & 1,912 & $63,7 \%$ & $63,7 \%$ \\
\hline 2 & 0,900 & $30,0 \%$ & $90,4 \%$ & 2 & 0,811 & $27,0 \%$ & $90,7 \%$ \\
\hline 3 & 0,286 & $9,6 \%$ & $100,0 \%$ & 3 & 0,275 & $9,3 \%$ & $100,0 \%$ \\
\hline \multirow{2}{*}{$\begin{array}{l}\text { Contribuciónal } \\
\text { componente } \\
\text { (Eigenvectors) }\end{array}$} & & & & \multirow{2}{*}{$\begin{array}{l}\text { Contribuciónal } \\
\quad \text { factor } \\
\text { (Eigenvectors) }\end{array}$} & & & \\
\hline & $\begin{array}{l}\text { Componen } \\
\text { te } 1\end{array}$ & $\begin{array}{c}\text { Component } \\
\text { e } 2\end{array}$ & - & & $\begin{array}{c}\text { Compone } \\
\text { nte } 1\end{array}$ & $\begin{array}{c}\text { Componente } \\
2\end{array}$ & - \\
\hline Isei oc. padre & 0,671 & $-0,205$ & - & $\begin{array}{c}\text { Isei oc. } \\
\text { encuestado }\end{array}$ & 0,648 & $-0,259$ & - \\
\hline $\begin{array}{c}\text { Educación } \\
\text { padre }\end{array}$ & 0,662 & $-0,263$ & - & $\begin{array}{l}\text { Educación } \\
\text { encuestado }\end{array}$ & 0,632 & $-0,327$ & - \\
\hline $\begin{array}{l}\text { Indice cap. } \\
\text { Social (de } \\
\text { lazos } \\
\text { familiares) }\end{array}$ & 0,331 & 0,942 & - & $\begin{array}{l}\text { Indice cap. } \\
\text { Social }\end{array}$ & 0,415 & 0,908 & - \\
\hline
\end{tabular}

Fuente: Elaboración propia en base a Encuesta Pi-Clases (2016)

\section{CUADRO 8}

Estructura factorial para orígenes sociales (estatus ocupacional, educación del padre y promedio de capital social accedido para lazos familiares) y de factores adquiridos (estatus ocupacional, educación y promedio de capital social)

\begin{tabular}{|c|c|c|c|c|c|c|c|}
\hline \multirow[b]{2}{*}{ Componente } & \multicolumn{3}{|c|}{ Componentes de factores adscriptos } & \multirow[b]{2}{*}{ Componente } & \multicolumn{3}{|c|}{ Componentes de factores adquiridos } \\
\hline & Total & $\begin{array}{c}\% \text { de la } \\
\text { varianza } \\
\text { explicada }\end{array}$ & $\begin{array}{c}\% \\
\text { acumulad } \\
0\end{array}$ & & Total & $\begin{array}{c}\% \text { de la } \\
\text { varianza } \\
\text { explicada }\end{array}$ & $\begin{array}{c}\% \\
\text { acumulad } \\
0\end{array}$ \\
\hline 1 & 2,056 & $68,5 \%$ & $68,5 \%$ & 1 & 2,248 & $74,9 \%$ & $74,9 \%$ \\
\hline 2 & 0,661 & $22,0 \%$ & $90,5 \%$ & 2 & 0,472 & $15,7 \%$ & $90,6 \%$ \\
\hline 3 & 0,282 & $9,5 \%$ & $100,0 \%$ & 3 & 0,279 & $9,4 \%$ & $100,0 \%$ \\
\hline \multirow{2}{*}{$\begin{array}{c}\text { Contribución } \\
\text { al } \\
\text { componente } \\
\text { (Eigenvectors } \\
\text { ) }\end{array}$} & & & & \multirow{2}{*}{$\begin{array}{c}\text { Contribución } \\
\text { al factor } \\
\text { (Eigenvectors } \\
\text { ) }\end{array}$} & & & \\
\hline & $\begin{array}{c}\text { Component } \\
\text { e } 1\end{array}$ & $\begin{array}{c}\text { Component } \\
\text { e } 2\end{array}$ & - & & $\begin{array}{c}\text { Component } \\
\text { e } 1\end{array}$ & $\begin{array}{c}\text { Component } \\
\text { e } 2\end{array}$ & - \\
\hline Isei oc. padre & 0,617 & $-0,333$ & - & $\begin{array}{c}\text { Isei oc. } \\
\text { encuestado }\end{array}$ & 0,592 & $-0,394$ & - \\
\hline $\begin{array}{c}\text { Educación } \\
\text { padre }\end{array}$ & 0,614 & $-0,363$ & - & $\begin{array}{l}\text { Educación } \\
\text { encuestado }\end{array}$ & 0,593 & $-0,376$ & - \\
\hline $\begin{array}{c}\text { Promedio } \\
\text { cap. social } \\
\text { (de lazos } \\
\text { familiares) }\end{array}$ & 0,493 & 0,869 & - & $\begin{array}{l}\text { Promedio } \\
\text { cap. social }\end{array}$ & 0,545 & 0,838 & - \\
\hline
\end{tabular}

Fuente: Elaboración propia en base a Encuesta Pi-Clases (2016)

En lo que refiere a los factores adscriptos (los orígenes sociales) se observa que el primer componente captura gran parte de la varianza $(60,4 \%$ y $68,5 \%$, respectivamente) y se encuentra compuesto 
principalmente por el estatus ocupacional y la educación del padre. Lo importante es que en ambos casos el segundo factor, compuesto principalmente por el capital social, explica una porción relevante de la varianza entre las variables (30,0 \% y 22,0 \%). Esto nos indica que los orígenes sociales no pueden ser reducidos a una dimensión compuesta por el estatus ocupacional y educación de los padres, sino que es más apropiada una mirada al menos bidimensional que incorpore el capital social.

Lo que ocurre para el caso de los factores adquiridos (estatus ocupacional, educación y capital social del encuestado) es similar. Tampoco estos pueden reducirse a una única dimensión, sino que el capital social conforma una segunda dimensión (aunque de menor relevancia que la conformada por los factores clásicos). ${ }^{9}$

\section{Conclusiones}

El capital social se ha introducido en los debates de estratificación y desigualdad de clases sociales a partir de las posibilidades que abre a los individuos de aprovechar sus relaciones sociales. Este trabajo presenta las maneras en que se ha abordado la medición de este fenómeno complejo, particularmente a partir del generador de posiciones. Desde una perspectiva teórica de redes, el generador de posiciones incorpora una serie de dimensiones del capital social: el volumen de recursos accedidos, los máximos recursos alcanzados y la heterogeneidad de los recursos. Este instrumento mide si las personas tienen o no contactos en una serie de ocupaciones (médicos, albailes, operarios de fábrica, empleados administrativos, etc.) y supone que esto implica el acceso a ciertos recursos.

La encuesta del PI-Clases utilizada en este trabajo es la primera en incorporar el generador de posiciones en la Argentina y el generador de posiciones se encuentra relativamente estandarizado a nivel internacional. Sin embargo, no hay una herramienta de uso común para obtener las medidas a partir de datos de encuesta. Entonces, este trabajo mostró los procedimientos técnicos requeridos para construir las medidas del generador de posiciones a partir de micro-datos de encuesta, incluyendo los módulos de sintaxis de Stata y SPPS, que pueden ser generalizados para utilizar en otras encuestas.

La medida de promedio de capital social es la que se correlaciona con mayor fuerza con las variables clásicas de estratificación (ocupación y educación), mientras que las medidas de total, máximo y rango tienen correlaciones más moderadas. A su vez, se observan desigualdades del acceso al capital social según clase social, que serán analizadas en profundidad en futuros trabajos.

La construcción de un índice de capital social a partir del análisis de factores principales mostró un primer factor compuesto por las dimensiones de rango, máximo y cantidad de contactos, y un segundo factor compuesto únicamente por la cantidad de contactos. Este análisis mostró que el capital social tiene distintas dimensiones y que pueden ser resumidas en un índice de capital social. A su vez, el análisis que incorpora los factores adscriptos y adquiridos mostró que los orígenes sociales y el estatus adquirido no son unidimensionales, sino que el capital social conforma una segunda dimensión, lo que justificaría su incorporación a modelos multidimensionales sobre la desigualdad social.

\section{REFERENCIAS}

Angelusz, R. \& Tardos, R. (1991). The Strength and Weakness of Weak Ties. Research Review, 3, 7-25.

Atria, R., Siles, M., Arriagada, I., Robison, L. y Whiteford, S. (comps.) (2003). Capital social y reducción de la pobreza en América Latina y el Caribe: en busca de un nuevo paradigma. Santiago de Chile: CEPAL.

Blumer, H. (1982). El interaccionismo simbólico: perspectiva y método. Barcelona: Hora.

Brunet, N. (2017). Estratificación ocupacional y retornos del capital social en la búsqueda de empleo. El caso de la ciudad de México. En P. Solís (Ed.), Desigualdad, movilidad social y curso de vida en la Ciudad de México (pp. 126-163). Ciudad de México: El Colegio de México. 
Burt, R. S. (1992). Structural holes: The social structure of competition. Cambridge Massachussetts: Harvard University Press.

Campbell, K. E., Marsden, P. V. \& Hurlbert, J. S. (1986). Name Generators in Surveys of Personal Networks. Social Networks, 13, 203-221.

Carrascosa, J. (2020). La importancia de los lazos sociales: clases sociales y mecanismos de acceso al empleo en el Área Metropolitana de Buenos Aires. Estudios Sociológicos De El Colegio De México, 39(115), 67-108. https://doi.o $\mathrm{rg} / 10.24201 /$ es.2021v39n115.1936

Chávez Molina, E. (2010). La construcción social de la confianza en el mercado informal. Los feriantes de Francisco Solano. Nueva Trilce Editorial.

Dalle, P. (2016). Movilidad social desde las clases populares: Un estudio sociológico en el área metropolitana de Buenos Aires (1960-2013). Buenos Aires: IIGG-CLACSO.

De Grande, P. (2010). Clases y lazos: la estratificación social de los vínculos interpersonales en grandes centros urbanos de la Argentina. VI Jornadas de Sociología de la UNLP “Debates y perspectivas sobre Argentina y América Latina en el marco del Bicentenario. Reflexiones desde las Ciencias Sociales”, 1-15.

De Grande, P. (2015). Estructura social y sociabilidad: ¿son desiguales las redes personales? Redes. Revista Hispana para el Análisis de Redes Sociales, 26(2), 15-39.

Durston, J. (2003). Capital Social: parte del problema, parte de la solución. Su papel en la persistencia y superación de la pobreza en América Latina y el Caribe. En R. Atria, M. Siles, I. Arriagada, L. Robinson y S. Whiterford (comps.), Capital social y reducción de la pobreza en América Latina y el Caribe: en busca de un nuevo paradigma (pp. 147-202). Santiago de Chile: CEPAL-Michigan State University.

Erickson, B. H. (1995). “Networks, Success, and Class Structure: A Total View”. Sunbelt Social Networks Conference. Charleston.

Espinoza, V., Rey, R. y Barozet, E. (2017). Incidencia del capital social en la explicación del logro ocupacional. V Seminario Internacional Desigualdad y Movilidad Social en América Latina. La Plata.

Feldman, S. y Murmis, M. (2002). Las ocupaciones informales y sus formas de sociabilidad: apicultores, albañiles y feriantes. En L. Beccaria, M. Feldman, I. González Bombal, G. Kessler, M. Murmis y M. Svampa (Eds.), Sociedad y Sociabilidad en la Argentina de los 90 (pp. 173-230). Buenos Aires: Biblos.

Ganzeboom, H. B. G., De Graaf, P. M. \& Treiman, D. J. (1992). A standard socio-economic index of occupational status. Social Science Research, 21(1), 1-56.

Ganzeboom, H. B. G. \& Treiman, D. J. (2010). International Stratification and Mobility File: Conversion Tools. Amsterdam: Department of Social Rearch Methodology.

Granovetter, M. S. (1973). The Strength of Weak Ties. American Journal of Sociology, 78, 1360-1380. https://doi.o $\mathrm{rg} / 10.1086 / 225469$

International Labour Office (ILO) (2012). International Standard Classification of Occupations: ISCO-08. Ginebra: ILO.

Kaiser, H. F. (1974). An Index of factor simplicity. Psychometrika, 39, 31-36.

Kessler, G. (2017). Explorando el capital social en Argentina. Diálogo Global, Vol 7(4), 43-47.

Kliksberg, B. y Tomassini, L. (Eds.) (2000). Capital social y cultura: claves estratégicas para el desarrollo. Santiago de Chile: CEPAL.

Lazarsfeld, P. F. (1973). De los conceptos a los índices empíricos. En A. Boudon y P. Lazarsfeld (Eds.), Metodología de las Ciencias Sociales. Buenos Aires: LAIA.

Li, Y., Savage, M. \& Warde, A. (2008). Social mobility and social capital in contemporary Britain. British Journal of Sociology, 59(3), 391-411. https://doi.org/10.1111/j.1468-4446.2008.00200.x

Lin, N. (1999a). Building a Network Theory of Social Capital. Connections, 22(1), 28-51. https://doi.org/10.1108/ 14691930410550381

Lin, N. (1999b). Social Networks and Status Attainment. Annual Review of Sociology, 25, 467-487.

Lin, N. (2001). Social Capital: A Theory of Social Structure and Action. Cambridge: Cambridge University Press. 
Lin, N. (2005). A Network Theory of Social Capital. En J. Van Deth \& G. Wolleb (Eds.), Handbook on Social Capital (pp. 50-69). Oxford: Oxford University Press.

Lin, N. \& Dumin, M. (1986). Access to Occupations Through Social Ties. Social Networks, 8, 365-385.

Mallimaci, F. y Graffigna, M. (2002). Constitución de redes y movimientos sociales solidarios como estrategia de satisfacción de necesidades. En F. Forni (Ed.), De la exclusión a la organización. Buenos Aires: Ciccus.

McPherson, M., Smith-Lovin, L. \& Cook, J. M. (2001). Birds of a Feather: Homophily in Social Networks. Annual Review of Sociology, 27, 415-444.

Merlinsky, M. G. (2001). Microemprendimientos y redes sociales en el conurbano. Balance y desafíos de la experiencia reciente. Buenos Aires: Eudeba.

Paredes, D., Carrascosa, J. y Lazarte, L. (2020). Lazos sociales: Una mirada desde el análisis de clases sociales. En R. Sautu, P. Boniolo, P. Dalle y R. G. Elbert (Eds.), El análisis de clases sociales: pensando la movilidad social, la residencia, los lazos sociales, la identidad y la agencia (pp. 215-252). Buenos Aires: CLACSO-IIGG.

Pearson, K. (1901). On Lines and Planes of Closest Fit to Systems of Points in Space. Philosophical Magazine, 2(11), 559-572.

Pérez, P. (2008). La inserción ocupacional de losjóvenes en un contexto de desempleo masivo. El caso argentino entre 1995 y 2003. Buenos Aires: Editorial Miño y Dávila.

Portes, A. (1998). Capital social: sus orígenes y aplicaciones en la sociología moderna. De Igual a Igual: el desafío del Estado ante los nuevos problemas sociales, 1-24.

Putnam, R. D. (1993). Making Democracy Work. Princeton: Princeton University Press.

Rey, R. (2017). El acceso al capital social y su distribución por clase social. V Seminario Internacional Desigualdad y Movilidad Social En América Latina. La Plata.

Savage, M., et al. (2013). A New Model of Social Class? Findings from the BBC's Great British Class Survey Experiment. Sociology, 47(2), 219-250. https://doi.org/10.1177/0038038513481128

Van der Gaag, M. (2005). The measurement of individual social capital. Groningen: Ph.D dissertation.

Van der Gaag, M. \& Snijders, T. (2004). Proposals for the Measurement of Individual Social Capital. En H. Flap \& B. Volker (Eds.), Creation and Returns of Social Capital: A New Research Program (p. 308). Londres: Routledge.

Van der Gaag, M., Snijders, T. \& Flap, H. (2008). Position Generator Measures and Their Relationship to Other Social Capital Measures (pp. 27-49). En N. Lin \& B. H. Erickson (Eds.), Social Capital: An International Research Program (pp. 27-48). Oxford: Oxford University Press.

Verhaeghe, P.-P. \& Li, Y. (2015). The position generator approach to social capital research: measurements and results. En Y. Li (Ed.), The Handbook of Research Methods and Applications on Social Capital (pp. 166-186). Cheltenham: Edward Elgar Publishing.

Völker, B. \& Flap, H. (1999). Getting Ahead in the GDR. Acta Sociologica, 42, 7-42.

Wyczykier, G. (2003). Informalidad y lazos sociales. Estudios del Trabajo, 26, 27-52. 


\section{Anexo:}

\section{CUADRO 9}

Matriz de correlaciones entre medidas de capital social y variables de estratificación social

\begin{tabular}{|c|c|c|c|c|c|c|c|c|c|c|c|c|c|c|}
\hline Variables & 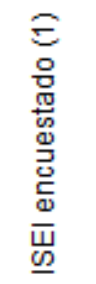 & 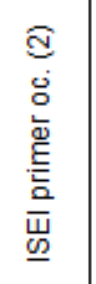 & 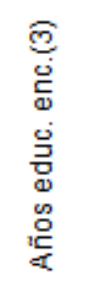 & 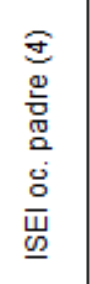 & 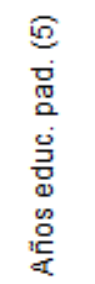 & 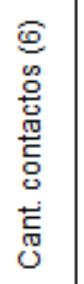 & 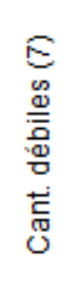 & 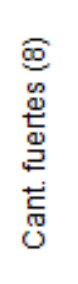 & 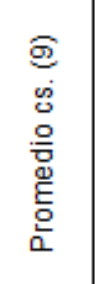 & 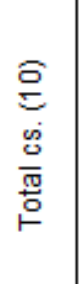 & 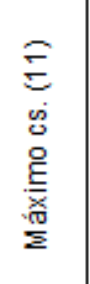 & 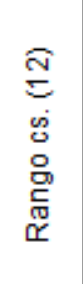 & 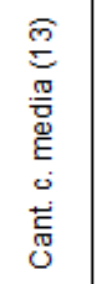 & 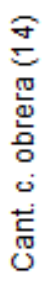 \\
\hline $\begin{array}{l}\text { ISEI encuestado } \\
\text { (1) }\end{array}$ & - & & & & & & & & & & & & & \\
\hline ISEI primer oc. (2) & 0,522 & - & & & & & & & & & & & & \\
\hline $\begin{array}{l}\text { Años educ. enc } \\
\text { (3) }\end{array}$ & 0,719 & 0,523 & - & & & & & & & & & & & \\
\hline ISEI oc. padre (4) & 0,469 & 0,362 & 0,499 & - & & & & & & & & & & \\
\hline $\begin{array}{c}\text { Años educ. pad. } \\
\text { (5) }\end{array}$ & 0,461 & 0,372 & 0,527 & 0,713 & - & & & & & & & & & \\
\hline $\begin{array}{l}\text { Cant. contactos } \\
\text { (6) }\end{array}$ & 0,108 & 0,053 & 0.140 & 0,111 & 0,104 & - & & & & & & & & \\
\hline Cant. débiles (7) & 0,124 & 0,065 & 0,159 & 0,119 & 0,103 & 0,824 & - & & & & & & & \\
\hline Cant. fuertes (8) & 0,006 & $-0,019$ & 0,006 & 0,012 & 0,006 & 0,658 & 0,348 & - & & & & & & \\
\hline Promedio c5. (9) & 0,576 & 0,448 & 0,574 & 0,439 & 0,433 & 0,203 & 0,191 & 0,038 & - & & & & & \\
\hline Total cs. (10) & 0,365 & 0,262 & 0,402 & 0,320 & 0,297 & 0,862 & 0,724 & 0.494 & 0,633 & - & & & & \\
\hline Máximo cs. (11) & 0,428 & 0,321 & 0,446 & 0,334 & 0,329 & 0,571 & 0,464 & 0,277 & 0,811 & 0,803 & - & & & \\
\hline Rango c5. (12) & 0,237 & 0,175 & 0,282 & 0,194 & 0,194 & 0,695 & 0,535 & 0,322 & 0,532 & 0,772 & 0,905 & - & & \\
\hline $\begin{array}{l}\text { Cant. c. medis } \\
\text { (13) }\end{array}$ & 0.429 & 0,314 & 0,465 & 0,355 & 0,356 & 0,793 & 0,675 & 0,465 & 0,684 & 0,964 & 0,803 & 0,725 & - & \\
\hline $\begin{array}{c}\text { Cant. c. obrers } \\
\text { (14) }\end{array}$ & $-0,427$ & $-0,357$ & $-0,430$ & $-0,319$ & $-0,333$ & 0,509 & 0,390 & 0,415 & $-0,640$ & 0,010 & $-0,224$ & 0,028 & $-0,121$ & - \\
\hline
\end{tabular}

Elaboración propia sobre la base de Elaboración propia en base a Encuesta Pi-Clases (2016).)

En cursiva, valores no significativos $=p>0.05$

\section{Notas}

1 Para detalles sobre los puntos en común y las diferencias entre las distintas teorías del capital (marxista/clásica, capital humano, capital cultural, capital social), ver Lin (1999a).

2 Lin (1999b) presenta una tabla que resume los principales hallazgos de trabajos con distintos instrumentos de medición (generador de nombres y generador de posiciones) en América del Norte, Europa y Asia. Van der Gaag, Snijders y Flap (2008, p. 43) presentan una tabla en la que proponen las formas de medición más adecuadas según si el estudio es de tipo general, de tipo focalizado en acciones instrumentales, focalizado en acciones, focalizado en metas específicas o si busca analizar componentes específicos de redes o relaciones.

3 El código "1" implica que conoce a un hombre, el "2" a una mujer, el " 3 " que no conoce a alguien con dicha ocupación y el "12" que conoce a un hombre y una mujer.

4 Otra manera de analizar los datos del generador es a partir de un análisis descriptivo de los lazos. Para ello, véase (Paredes, Carrascosa y Lazarte, 2020).

5 La cantidad de casos cambia según la variable. Siguiendo las recomendaciones de la bibliografía internacional para el armado del generador de posiciones, el promedio, el máximo y total de capital social se calcula únicamente para quienes tienen al menos un contacto y el rango, para quienes tienen al menos dos contactos.

6 En tonos de azul, las correlaciones positivas; en tonos de rojo, las correlaciones negativas; y en blanco, la ausencia de correlación. Las formas más ovaladas implican mayor fuerza de la correlación.

7 La fórmula para obtener la medida compuesta para cada caso sería la siguiente:

Utilizar la medida compuesta o el índice (componente 1) es indistinto ya que son equivalentes (se correlacionan $\mathrm{r}=1$ ). Se diferencian en los valores que adquieren: el índice tiene forma de curva normal con una media de 0; en cambio, la medida compuesta tiene una media de 25 y no puede adquirir valores negativos. 
8 Se utilizan el promedio y el índice (que es equivalente a la medida compuesta) en tanto son las medidas que han mostrado ser más robustas en distintos análisis no mostrados aquí y las que mayor correlación han mostrado con las otras variables.

9 En ninguno de los casos se alcanza a cumplir completamente el criterio de Kaiser (tener en cuenta únicamente factores con eigenvalues mayores que 1), pero sí puede considerarse el segundo factor como aceptable a partir del criterio de varianza, según el cual se contemplan los factores que alcancen a explicar entre $70 \%$ y $80 \%$ de la varianza en conjunto, ya que, según el caso, el primer componente alcanza únicamente entre el 60,4 \% y el 74,9\% de varianza explicada. 